attention should be paid to the activities of male clients of prostitutes.

We thank Dr Ivan Tait and all the staff working at the genitourinary hospital clinics in Glasgow for their help and support over the past two years. This study was funded by the Medical Research Council. The Public Health Research Unit is supported by the Chief Scientist Office of the Scottish Home and Health Department and the Greater Glasgow Health Board. The opinions expressed in this paper are

not necessarily shared by the Scottish Home and Health Department.

1 McKeganey N, Barnard M, Leyland A, Coote I, Follet E. Female streetworking prostitution in Glasgow. BMf 1992;305:801-4.

McKeganey N, Barnard M. AIDS, drugs and sexual risk: lives in the balance. Buckingham: Open University Press, 1992.

Leonard TL, Freund M, Platt J. Behavior of clients of prostitutes. Am $\mathcal{f}$ Public Health 1989;79:903.

4 Day S, Ward H, Harris JRW. Prostitute women and public health. $B M Y$ 1988;297:1585.

(Accepted 9 fuly 1993)

\title{
Current practices in neonatal intensive care in the United Kingdom
}

\author{
C Day, R A Primhak
}

\section{Jessop Hospital for \\ Women, Sheffield \\ C Day, consultant \\ paediatrician \\ R A Primhak, consultant \\ paediatrician}

Correspondence to:

Dr C Day, Airedale Genera

Hospital, Steeton, Keighley,

West Yorkshire BD20 6TD

$B M F$ 1993;307:362
We set out to discover if there were any consistencies in clinical practices among United Kingdom nurseries with facilities for neonatal intensive care.

\section{Present survey and results}

A questionnaire was sent to a named consultant within each unit with neonatal intensive care cots listed in the directory of intensive care units. Details were sought regarding agreed policies for the following: birth weight or gestational age cut off below which intensive care was not offered; routine intubation and ventilation of very low birthweight babies; prophylactic drugs given to very low birthweight babies; use of sedation, paralysis, and antibiotics during ventilation; and whether a baby with stage 3 hypoxic-ischaemic encephalopathy would receive mechanical ventilation for respiratory failure.

Of the 140 units circulated, $106(76 \%)$ replied. Thirty seven $(35 \%)$ of the responding units did not offer intensive care below a certain birth weight or gestation. Among the 32 units that specified a gestational age the mode was 24 weeks (range 20-26). A birth weight cut off was specified by 17 units and generally this was $500 \mathrm{~g}$ (range 500-650).

Fifty two (49\%) units electively intubated babies below a specified gestational age. The modal gestational age cut off for elective intubation was 30 weeks (range 26-34). Once the infant was resuscitated, $51(48 \%)$ units continued ventilation in babies below a certain size until blood gas criteria justified withdrawal. The cut off point for this form of elective ventilation was based on gestation in all but two units (mode 28 weeks, range 26-34), but many specified birth weight as well (mode $1000 \mathrm{~g}$, range 750-1250).

Opinion was evenly divided on the management of

Frequency of routine practices in 106 neonatal units in the United Kingdom

\begin{tabular}{lc}
\hline & $\begin{array}{c}\text { No }(\%) \\
\text { of practices }\end{array}$ \\
\hline Ethamsylate in very low birthweight babies & $28(26)$ \\
Vitamin E in very low birthweight babies & $21(20)$ \\
Volume expanders in very low birthweight babies & $10(9)$ \\
Sedation of all ventilated babies & $35(33)$ \\
Antibiotics in all ventilated babies & $72(68)$ \\
\hline
\end{tabular}

stage 3 hypoxic-ischaemic encephalopathy. Thirty one $(29 \%)$ units would never ventilate a baby with this condition, $34(32 \%)$ would routinely ventilate such a baby in respiratory failure, and 37 (35\%) had no clear practice. The numbers of units with other routine practices are shown in the table.

When the units were divided into "large" (more than four intensive care cots) and "small" there was no significant difference in any mangement practice between them.

\section{Comment}

We have shown wide variations in clinical practice in neonatal intensive care in the United Kingdom, unrelated to the size of the unit. When two groups of clinicians differ in their use of an invasive treatment either one group is doing something unnecessary and potentially harmful or the other group is failing to give optimal care.

In a Danish questionnaire based study ${ }^{1}$ one third of units would not routinely resuscitate an infant delivered at 26 weeks. In the United Kingdom seven yeas later almost all units would do so, but over one third of units still operated some cut off, with considerable variation between units. About half the units surveyed electively intubated and ventilated small infants, despite little published evidence on the subject. A retrospective study using historical controls suggested that more aggressive resuscitation policies were associated with a reduction in the mortality from hyaline membrane disease. ${ }^{2}$ However, this practice has a potential morbidity, and when it is combined with elective ventilation for a longer period it may commit the baby to a cascade of intensive care procedures.

Neonatal intensive care has a long history of jumping on the wrong bandwagons, ${ }^{3}$ and many current practices have been introduced without objective evaluation. Collaborative randomised trials may resolve some issues, but it is not always possible to perform a randomised double blind controlled trial of every new management technique. If standardised outcome data were routinely collected the introduction of these new practices could at least be monitored by comparing outcomes in units which follow different management practices. Anecdote and intuition are no longer adequate guides to management in neonatal intensive care units.

\footnotetext{
Greisen G. Choice of treatment in very premature deliveries. A nationwide questionnaire. Ugeskr Laeger 1989;151:1612-4.

2 Robson E, Hey EN. Resuscitation of preterm babies at birth reduces the risk of hyaline membrane disease. Arch Dis Child 1982;57:184-6.

Silverman WA. Retrolental fibroplasia-a modern parable. New York: Grune and Stratton, 1980:69-89.

(Accepted 28 May 1993)
} 